\title{
Opinion paper: emerging markets, emerging strategies under the genomic revolution
}

\author{
J. Labatut ${ }^{\dagger}$ \\ INRA, SAD UMR AGIR 1248, Chemin Borderouge, 31326 Castanet Tolosan, France
}

(First published online 11 February 2015)

Genomic selection (GS) is widely considered as a technological breakthrough in the animal breeding industry. However, this revolution is far from being 'only' a technological one. The genomic revolution is also organizational. Organizational implications of genomic innovations in livestock industries have been barely studied, although public-private partnerships, companies merging, or innovation and data management have been key questions for research and industry actors. In the context of such a technological leap forward, actors introducing new technologies often tend to exclude certain players and focus on optimizing the technological side first while neglecting other social aspects. If opportunities and threats in terms of technological changes are well identified by geneticists, organizational opportunities and threats stay mostly out of scientific studies, although some of them are pointed out. For example, Boichard and Brochard (2012) highlighted the fact that future challenge for phenotyping is to revisit the organization of data collection and contractual relations with farmers. An interdisciplinary group of social scientists (management sciences) and geneticists studied such organizational changes in the French breeding industry (Labatut et al., 2014). Did GS destabilize historical relations among actors and how? What are the risks and opportunities of new forms of cooperation and competition? How to define new relations between farmers and breeding companies? These were the questions addressed in this research group.

Analysing organizational aspects of breeding activities implies to consider the specificity of genetic resources management. One of the reasons why GS led to major organizational changes in the realm of animal breeding compared with what could happen in the plant breeding industry rests upon the fact that animal genetic resources have always been managed as common goods (Ostrom et al., 1999; Labatut et al., 2013); there is no private owner of a breed, contrary to a plant variety, and it is difficult to limit access to the resource. However, what is managed 'in common' in breeding activities is not only the biological pool. It is also the information pool.

\footnotetext{
${ }^{\dagger}$ E-mail: julie.labatut@toulouse.inra.fr
}

Managing genetic resources or creating genetic gain requires producing and managing data. Until now, the pedigree of hundreds of thousands of animals and their performances has been public information and was not in the hands of a single company. Compared with plant breeding, the technical constraints of cattle breeding under a progeny-testing scheme thus implied cooperation between public research, breeding companies, breeders' associations and farmers. The organization of breeding activities was mostly based on a national and open system for management of genetic data and research activities organized on the basis of mutual principles (in most countries, it was not possible for each private company to invest enough on research and development of new breeding criteria, for example). A common management structure for each breed used to define breeding objectives was common for all breeding companies. This widespread public and cooperative regime of animal selection was of course carried out with some variations according to each country (depending on the role of the State in organizing breeding activities, for example). In such a regime, innovation was a public good, and individual and private strategies of innovation appropriation were limited owing to low private funding. This organization allowed high efficiency in terms of genetic gain under the progeny-testing regime.

Since 2009 and the 'genomic revolution', the breeding industry has faced a period of both increasing opportunities and increasing uncertainty. We observed organizational changes in four domains of breeding activities related to R\&D: breeding companies' activities, farmers' practices and breeds' governance. In each domain, we identified risks and opportunities in actual changes.

Within R\&D activities, we observed that the development of GS was at first closely related to the development of new forms of cooperation to build large reference populations (consortia, public-private partnerships, etc.). Once the technology has been launched, such relations of cooperation have been sometimes difficult to maintain for R\&D projects. Some breeding companies developed research on their own breeding criteria and collected private data as an instrument for competitive advantage. We also observed an increase in number of public and private research institutions involved in genomic research for livestock, 
owing to the market opportunity opened by genomic technologies. The historical research actors are not the unique players anymore. Such changes in R\&D activities offer the opportunity of increasing innovation diversity to better meet the users' needs. However, the privatization of R\&D may also lead to losses in scale economies and research efficiency, and decrease research and breeding capacities dedicated to small breeds.

Concerning relations between breeding companies, we observed various strategies. More and more companies decided to merge, motivated by increasing scale economies, sharing investment on new technological development and increasing market shares. Some companies decided to pool only some resources while keeping separate entities. They shared specific investments, bulls or access to new technologies such as sexing technologies. Again, if GS has seen the development of such new forms of cooperation among competitors (which is sometimes called the neologism of 'co-opetition'), we also recorded cases where the development of GS led to increased competition between breeding companies which were historic partners, breaking previous relations of cooperation, for example, when one of the companies records and selects for a new breeding trait and does not share information on it in order to develop or maintain competitive advantage, as mentioned earlier. Similar changes can also be identified concerning the production and management of data from new phenotypes. Breeding companies develop contractual relationships with data providers (milk recording companies or associations, abattoirs, etc.). Here again, the opportunities are to share knowledge, investment and structures to be more efficient, but risks are increasing individualism, loss of efficiency and loss of territorial competences when specific activities are grouped in only one place for reducing costs.

GS also impacted the relations between industry actors and farmers. First, GS radically changed the market for genetics, with the development of new types of goods and services. In terms of goods, beside progeny-tested bulls appeared 'genomic' bulls, that is, bulls evaluated based only on their genomic information. The change is not limited only to the source of information used to compute their breeding value. The turn over of genomic-tested bulls is much more important than for progeny-tested ones. Their reliability is not the same either. On the farmers' side, this new type of bulls called sometimes for a complex change of practices, implying to give up the previous 'star system', which was promoting very few top famous bulls, and accept the 'anonymization' of bulls. More and more farmers are asked to choose a set of desired characteristics, a 'profile', not a single bull anymore. For our colleagues in the dairy sheep genetics, the impossibility of choosing a specific sire/ram is just 'business as usual', when one has to manage 400 ewes and when frozen semen cannot be used. In dairy cattle, even if the end of the 'star system' will help decreasing inbreeding, farmers can perceive this change in practice as a loss of competences. Mating plans may become an activity increasingly transferred from farmers to breeding companies, as well as the whole reproduction activity, for example, through heifers' stations. Thus, implications for farmers' profession have to be further studied: are we going towards a breeding system similar to poultry or swine, where farmers are more workers guided by large industries rather than independent managers? In terms of services, GS also brought a new service on the market, the service of genomic evaluation. Before GS, evaluation was not a service that one could buy without having been involved for a long period in a breeding programme. Opened for females, and more recently for sires in some countries, this new service is an opportunity for private actors to develop and sell their own evaluation tools, and for individual farmers to know the genetic value of their animals and sell them based on this information without participating in any breeding programmes. These changes raise questions on how to build trust into a new type of breeding value and in new providers of genomic evaluation tools. Although some breeding companies were taking advantage of a potential distrust in genomic evaluation with moderate reliabilities to develop a marketing message on the importance of progeny testing, other companies (sometimes 'non-historic' ones in the livestock industry) can sell evaluation tools without any possibilities for farmers to know the reliability of their results. How to ensure the neutrality and objectivity of the competing providers of genomic evaluations? If these new goods and services are unquestionable opportunities for improving herd management, several risks can be identified, such as distrust in genetic evaluations, opportunism or lack of knowledge on farmers' needs and practices.

GS also participated in changes in breed governance. In France, the GS landscape, breed associations have small investment capacities but an important political role as collective 'owners' of a breed, deciding its selection objectives. In France, in the past decade, several types of relations have been observed between breeding companies and breed associations, going from clear opposition and competition to close partnership or even global integration of the two 'sides' of management of a breed in a unique organization. However, the actual increasing development of private breeding strategies and private breeding criteria can raise the question of the common management of breeds. Are we going to move from breeds to brands? Here again, there are opportunities in ensuring partnership between the artificial insemination industry and breed associations to favour legitimacy of breeding activities and meet users' needs. When such partnership is lost, the risks are a decrease in breeders' implication and a decrease of legitimacy: users are also manufacturers of genetic progress.

Biotechnological innovations are never black or white, good or bad; they are complex, multifaceted and can bring as many opportunities as they can raise problems and questions. GS has been launched because it could break a deadlock and open a new world of solutions for future needs in the livestock industry. However, the organizational implications of such an innovation need to be taken into account in order to prevent the inherent risks of such changes. Cooperation is paradoxical, as we have seen, while actors (research, industry and breeders) have increasing interests in cooperating (huge research investment, efficiency of a new 
technology and innovation dynamics), cooperation is increasingly more difficult: the less the objects of cooperation are defined, the harder cooperation is. If successes are obtained, maintaining cooperation and partnership is a longrun activity in itself. When building new partnerships or consortia, defining evolving rules of coordination and collective identity is as important as working on the object of cooperation. The few elements described here are the result of an analysis of organizational changes in France. An international analysis needs to be developed for taking advantage of cross-learning and other experiences.

\section{Acknowledgements}

The author thanks Vincent Ducrocq, Didier Boichard, JeanMichel Astruc, Gilles Lagriffoul, Francis Barillet and Laurent
Griffon for their help in this research project, and France Génétique Elevage, UNCEIA and the Métaprogramme SELGEN (INRA) for funding it.

\section{References}

Boichard D and Brochard M 2012. New phenotypes for new breeding goals in dairy cattle. Animal 6, 544-550.

Labatut J, Allaire G and Aggeri F 2013. Etudier les biens communs par les changements institutionnels: regimes de propriété autour des races animales face à l'innovation génomique. Revue de la Régulation 14, Retrieved from http:/l regulation.revues.org/10529

Labatut J, Astruc J-M, Barillet F, Boichard D, Ducrocq V, Griffon L and Lagriffoul G 2014. Implications organisationnelles de la sélection génomique chez les bovines et ovins laitiers en France: analyses et accompagnement. INRA Productions Animales 27, 303-315.

Ostrom E, Burger J, Field B, Norgaard B and Policansky D 1999. Revisiting the commons: local lessons, global challenges. Sciences 284, 278-282. 